\title{
Evidence for a major gene affecting the transition from normoglycaemia to hyperglycaemia in Psammomys obesus
}

\author{
J Hillel $^{1}$, D Gefel ${ }^{2}$, R Kalman ${ }^{3}$, G Ben-Ari ${ }^{1}$, L David ${ }^{1}$, O Orion ${ }^{4}$, MW Feldman ${ }^{5}$, H Bar-On ${ }^{6}$, S Blum ${ }^{1}$,

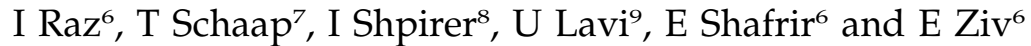 \\ ${ }^{1}$ The Robert H Smith Institute of Plant Sciences \& Genetics, The Hebrew University of Jerusalem, Rehovot 76100, Israel; ${ }^{2}$ Department of \\ Medicine-C, Barzilai Medical Center, Ashkelon 78306, Israel; ${ }^{3}$ The Authority for Research Animals, The Hebrew University of Jerusalem, \\ Israel; ${ }^{4}$ Institute of Evolution, University of Haifa, Mt. Carmel, Haifa 31905, Israel; ${ }^{5}$ Department of Biological Sciences, Stanford \\ University, Stanford, CA 94305-5020, USA; ' Diabetes Research Center, Hadassah University Hospital, Jerusalem 91120, Israel; \\ ${ }^{7}$ Department of Human Genetics, Hadassah Medical Center, Jerusalem 91120, Israel; ${ }^{8}$ Pulmonary Institute, Assaf Harofeh Medical \\ Center, PO Beer Yaacov, Zerifin 70300, Israel; 'Institute of Horticulture, ARO-Volcani Center, PO Box 6, Bet-Dagan 50250, Israel
}

\begin{abstract}
We investigated the mode of inheritance of nutritionally induced diabetes in the desert gerbil Psammomys obesus (sand rat), following transfer from low-energy (LE) to highenergy (HE) diet which induces hyperglycaemia. Psammomys selected for high or low blood glucose level were used as two parental lines. A first backcross generation $\left(\mathrm{BC}_{1}\right)$ was formed by crossing $F_{1}$ males with females of the diabetesprone line. The resulting $232 \mathrm{BC}_{1}$ progeny were assessed for blood glucose. All progeny were weaned at 3 weeks of age (week 0), and their weekly assessment of blood glucose levels proceeded until week 9 after weaning, with all progeny maintained on HE diet. At weeks 1 to 9 post weaning, a clear bimodal distribution statistically different from unimodal distribution of blood glucose was observed, normoglycaemic and hyperglycaemic at a $1: 1$ ratio. This ratio is expected at
\end{abstract}

the first backcross generation for traits controlled by a single dominant gene. From week 0 (prior to the transfer to HE diet) till week 8, the hyperglycaemic individuals were significantly heavier $(4-17 \%)$ than the normoglycaemic ones. The bimodal blood glucose distribution in $\mathrm{BC}_{1}$ generation, with about equal frequencies in each mode, strongly suggests that a single major gene affects the transition from normo- to hyperglycaemia. The wide range of blood glucose values among the hyperglycaemic individuals $(180$ to $500 \mathrm{mg} / \mathrm{dl}$ ) indicates that several genes and environmental factors influence the extent of hyperglycaemia. The diabetesresistant allele appears to be dominant; the estimate for dominance ratio is 0.97 .

Heredity (2005) 95, 158-165. doi:10.1038/sj.hdy.6800701; published online 1 June 2005

Keywords: Psammomys obesus; backcross; bimodal distribution; QTL; type-2 diabetes; major gene

\section{Introduction}

Type 2 diabetes (T2D) is among the most common chronic human diseases, affecting almost $8 \%$ of the adult population and $19 \%$ of people above the age of 65 years in the United States (Nathan, 2002). The aetiology of this disorder is considered to be multifactorial, involving genetic and environmental effects (Poulsen et al, 1999). The involvement of genetic control of diabetes in human populations is also evidenced from the finding that certain ethnic groups exhibit relatively high prevalence of T2D (eg Pima Indians, Polynesians Australian Aborigines, etc) in comparison to other population with lower frequency (Zimmet et al, 2001). Maturity-Onset Diabetes of the Young (MODY) is a genetically and clinically heterogeneous subgroup of T2DM with earlyonset autosomal dominant inheritance and a defect in

Correspondence: J Hillel, The Robert H Smith Institute of Plant Sciences $\mathcal{E}$ Genetics, The Hebrew University of Jerusalem, Rehovot 76100, Israel. E-mail: Hillel@agri.huji.ac.il

Received 23 July 2004; accepted 13 April 2005; published online 1 June 2005 insulin secretion (Tsigos et al, 2002). MODY has been the most extensively studied monogenic form of T2D and six known MODY subtypes identified to date are caused by mutations in genes encoding Glucokinase and five B-cellspecific transcription factors (Pruhova et al, 2003) A second monogenic form has been detected as a mutation in the mitochondrial DNA (Alcolado and Thomas, 1995).

The study of animals with nutrition-induced diabetes renders an opportunity to uncover the characteristics of T2D. An appropriate animal model for the T2DM research is the gerbil Psammomys obesus (often nicknamed 'sand rat'). Psammomys is a herbivorous rodent, subsisting on low-energy (LE) diet in the Israeli desert, where they feed mainly on electrolyte-rich saltbush (Atriplex halimus). There is no evidence that ever a hyperglycaemic Psammomys was encountered in its native habitat, and no diabetogenic mutation was discovered in the colonies of this animal. However, in captivity, on a relatively highenergy (HE) nutrition of $3.1 \mathrm{kcal} / \mathrm{g}$, as compared with a $2.4 \mathrm{kcal} / \mathrm{g}$ maintenance LE diet, hyperinsulinaemia and hyperglycaemia, and weight gain occur in most animals (Kalman et al, 1993). A genetic variability in diabetes susceptibility within the natural population has been 
observed. Consequently, we have initiated a selection program to achieve divergent diabetes-prone (DP) and diabetes-resistant (DR) lines (Kalman et al, 1993; Ziv and Kalman, 2000). The DP line, 7-14 days following the transfer to $\mathrm{HE}$ diet, is characterized by galloping hyperinsulinaemia, and later by hyperglycaemia. The selection of DR animals was aimed to establish a line of Psammomys that did not develop hyperglycaemia on $\mathrm{HE}$ diet. At present, about $90 \%$ of the animals fulfilled this criterion, following $>20$ generations of positive assortative mating. The percentage of animals with normal insulin and glucose levels rose slowly from one generation to the next one. The difference in the digestible energy consumed was attributed to be responsible for the DP and DR line differences. The energy cost for a gain of $1.0 \mathrm{~g}$ in body weight was $6.15 \mathrm{kcal}$ among Psammomys from the DP line, irrespective of the diet type consumed by the animals. By contrast, the energy cost for weight gain in the DR line animals was about $50 \%$ higher, at $9.3 \mathrm{kcal} / \mathrm{g}$ (Ziv and Kalman, 2000).

Diet-induced 'diabesity' (collusion of diabetes and obesity) in Psammomys (Shafrir, 1996) involves attenuation of insulin action, triglyceride metabolism and augmentation of lipoprotein lipase activity (Chajek-Shaul et al, 1988; Kanety et al, 1994; Ikeda et al, 2001). All these features lead to a metabolic state that is superimposed on a native 'thrifty metabolism' (Coleman, 1978), which might be seen as a peculiar natural adaptation to life in areas where only LE food is available. The artificial laboratory conditions of freely accessible affluent diet create a continuous input of energy, leading to hyperinsulinaemia, downregulation of insulin receptor signal transduction, a profuse hepatic lipogenesis and storage of triglycerides in adipose tissue. In the next stage, hyperglycaemia develops with increasing demand for insulin, thus leading to depletion of insulin from pancreatic $\beta$-cells (Shafrir et al, 1999a). The genetic predisposition of the DP line determines the development of 'diabesity' in animals only when they are maintained on a HE diet, whereas the DR animals do not develop these untoward changes. The role of genetic factors on one hand and dietary conditions on the other seem to be similar in humans and thus render development of T2D in Psammomys as an excellent model for the study of this multifactorial trait.

\section{Subjects, materials and methods}

\section{Experimental animals}

We used animals from the two divergently selected lines DR and DP as parents. Crosses and familial design are summarized in Figure 1. Three $F_{1}$ individuals, 2RG, 3RG (full-sibs) and 4RG, were obtained from a cross between two Psammomys males of the DR line and two females of the DP line. The first backcross generation $\left(B_{1}\right)$ was formed by a cross between each of three F1 males and 12-15 DP productive females, resulting in $267 \mathrm{BC}_{1}$ progeny: 120 from $2 \mathrm{RG}$ and 15 dams, 87 from $3 \mathrm{RG}$ and 13 dams, 60 from 4RG and 12 dams. Data on blood glucose were collected for nine post-weaning weeks on 232 individuals (some of the 267 animals died and some were not recorded for technical reasons). The missing 35 progeny were excluded from all analyses, and the number of recorded progeny during the experimental period varied from 202 at week 6 to 227 at week 0 .

Animals were held in polypropylene shoebox-type cages on autoclaved white wood shavings. The animals were housed at the animal facility under light cycle conditions $(12: 12 \mathrm{~h})$ at $22 \pm 2^{\circ} \mathrm{C}$. Fresh air $(100 \%)$ was supplied at 12-15 air changes per hour.

Psammomys were fed on two types of diet. The pelleted LE rodent diet, produced by Koffolk, Tel-Aviv, Israel, was supplied during matings. The HE diet, an extruded rodent maintenance diet produced at the Weizmann Institute in Rehovot, Israel, was supplied from weaning for 9 weeks until the end of the experimental period. Both diets are composed of relatively similar ingredients.

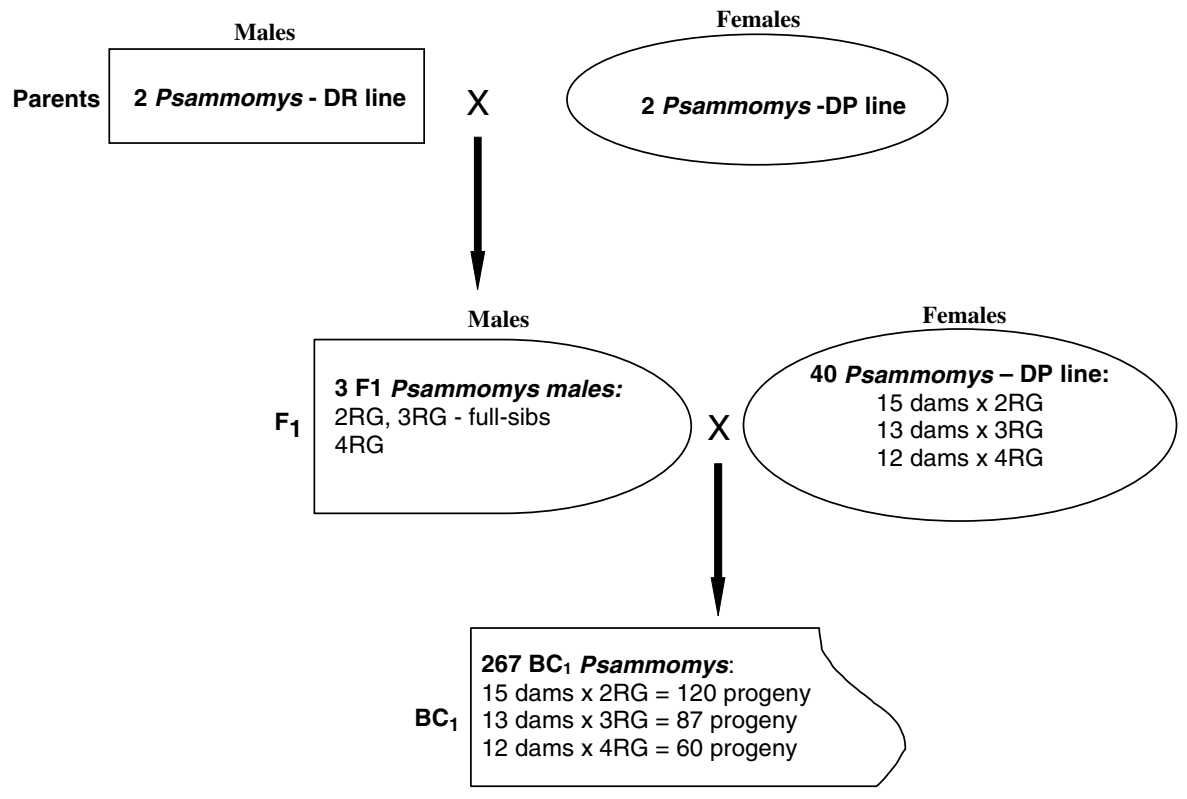

Figure 1 Design of the resource family. 
Although the total 'crude' energy is similar, the digestible portion of each diet is different, $2.4 \mathrm{kcal} / \mathrm{g}$ in the LE diet and $3.1 \mathrm{kcal} / \mathrm{g}$ in the HE diet. This portion represents $56.4 \%$ of the total dry material content in the LE diet and $82 \%$ of the total dry material content in the HE diet. Both diets were unautoclaved and put on the bottom of the cage (rather than on the grid). Tap water was supplied in 500-ml bottles equipped with zipper tubes. Food and water were supplied ad libitum.

\section{Experimental procedures and assays}

F1 males and all $\mathrm{BC}_{1}$ Psammomys were held individually from weaning (week 0 ) on $\mathrm{HE}$ diet for 9 weeks. Blood glucose and body weight were monitored weekly. Blood glucose tests (non-fasting) were performed on blood withdrawn from the tip of the tail with Glucometer Elite (Bayer, Elkhart IN, USA). All tests and measurements were performed in the morning hours (0800-1100 h). All procedures were performed according to the regulations of the Institutional Animal Care Committee.

\section{Maximum likelihood estimate and test for bimodality}

To test for bimodality, a null hypothesis $\mathrm{H}_{0}$ was made that the trait distribution density (TDD) is unimodal, while the alternative hypothesis $\mathrm{H}_{1}$ : TDD is bimodal.

When hypothesis $\mathrm{H}_{0}$ is rejected at some significance level (say, 0.001), bimodality is considered to exist.

Bimodality was quantified by the separation of the two peaks.

The unimodal distribution is expressed as:

$$
F_{\mathrm{U}}(x)=A_{\mathrm{U}} \exp \left\{-(x-\mu)^{2} / 2 \sigma^{2}\right\},
$$

where $A_{\mathrm{U}}=1 / \sqrt{2 \pi \sigma}$, while the bimodal mixture is expressed as:

$$
\begin{aligned}
F_{\mathrm{B}}(x)= & A\left(\sigma_{1}\right) \exp \left\{-\left(x-\mu_{1}\right)^{2} / 2 \sigma_{1}^{2}\right\} \\
& +A\left(\sigma_{2}\right) \exp \left\{-\left(x-\mu_{2}\right)^{2} / 2 \sigma_{2}^{2}\right\}
\end{aligned}
$$

Based on this approach, four statistics have been estimated: means $\left(\mu_{i}\right)$, and standard deviations $\left(\sigma_{i}\right)$ ( $i=1$ or 2 ) with amplitude

$$
A\left(\sigma_{\mathrm{i}}\right)=1 /\left(2 \sqrt{2 \Pi} \sigma_{\mathrm{i}}\right)
$$

The fitting was carried out by using the log likelihood functions $L\left(\mathrm{H}_{1}\right)$ and $L\left(\mathrm{H}_{0}\right)$. The likelihood functions asymptotically converge to $\chi^{2}$ distributions and the significance is tested against $\chi^{2}$ with two degrees of freedom.

$$
\chi_{(d=2)}^{2}=4.6\left(L\left(H_{1}\right)-L\left(H_{0}\right)\right)
$$

Once $F B(x)$ is fitted to a bimodal TDD, the degree of bimodality can be quantified as 'bimodal separation' (Zhang et al, 2003):

$$
\mathrm{S}=\left(\mu_{1}-\mu_{2}\right) /\left(2 \sigma_{1}+2 \sigma_{2}\right)
$$

\section{Estimation of genetic effects}

In estimating the additive effect $(d)$ and the dominant effect $(h)$ of a quantitative trait locus (QTL), we followed the approach and nomenclature of Mather and Jinks (1971), see Table 1. For estimating $m$ - the midpoint between values of the two homozygotes, $d$ - the genetic additive effect and $h$ - the genetic dominance effect, we assumed that the distribution of glucose levels in week 0 (prior to HE diet) represents the phenotypic distribution
Table 1 Linear models for the estimation of the additive genetic effect ' $d$ ' and the dominance effect ' $h$ '

\begin{tabular}{lllccc}
\hline Week & Phenotype & $\begin{array}{c}\text { Expected } \\
\text { genetic value }\end{array}$ & $X_{1}=m$ & $X_{2}=d$ & $X_{3}=h$ \\
\hline$i>0$ & $\begin{array}{l}\text { Distr. 1, below } \\
\text { median, } \mu_{\mathrm{L}}=87.5\end{array}$ & $\mathrm{Aa}=m+h$ & 1 & 0 & 1 \\
$i>0$ & $\begin{array}{l}\text { Distr. 2, above } \\
\text { median, } \mu_{\mathrm{H}}=305.5\end{array}$ & $\mathrm{aa}=m+d$ & 1 & 1 & 0 \\
0 & All, $\mu=91.2$ & $\mathrm{AA}=m-d$ & 1 & -1 & 0 \\
\hline
\end{tabular}

$\mu_{\mathrm{L}}$ and $\mu_{\mathrm{H}}$ are the maximum likelihood estimates for the 'Low' and for the 'High' distributions.

of normoglycaemic animals (which could stand for the distribution of homozygotes of the DR allele, given a single-gene inheritance). Therefore, levels of week 0 were used to represent the distribution of $(m-a)$ values for all the experimental weeks in this analysis. For a single gene, the BC1 generation contains two genotypes: heterozygotes and homozygotes for the recessive allele in a 1:1 ratio. For each week (1-9) of the experiment the population was divided into two subgroups, below and above the median glucose level, as expected from a 1:1 ratio of $B_{1}$. Individuals of the higher subgroup were regarded as homozygotes for the DP allele and were attributed the $(m+d)$ value. Individuals of the lower subgroup were regarded as heterozygotes and therefore assigned the $(m+h)$ value.

Separately for each experimental week, the genetic effects $(d$ and $h$ ) were estimated by multiple regression analysis using dummy variables $(1,0,-1)$ (Neter and Wasserman, 1974). For each week separately, glucose values were used as dependent variables. To the $n_{i}$ values of glucose in week $i, 227$ values of week 0 were added. So in week $i$, a string of $227+n_{i}$ values constituted the independent variable at week $i$. Three independent variables for estimating the genetic effects were defined as follows (see Table 1): For $X_{1}$ that estimates $m$, values of 1 were given to all rows. For $X_{2}$ that estimates $d$, a value of 1 was given to animals (at week $i, i>0$ ) of glucose level above the median, a value of 0 to animals below the median, and a value of -1 to animals of week 0 that were joined. For $X_{3}$ that estimates $h$, the value 1 was given to all animals below the median and the value 0 was given to animals above the median and to records of week 0 . Statistical analyses were carried out using the JMP 4.0 software (SAS Institute Inc.). Prior to the various analyses carried out, effects of the gender and season of birth on blood glucose levels were examined. As none of these effects were statistically significant in the various weeks, no adjustment for these exogenous factors was needed.

\section{Results}

\section{Phenotypic distribution of glucose levels}

Phenotypic distributions of glucose levels in the blood were graphed for weeks 0-9 (Figure 2). The distribution at week 0 , when animals were not subjected to the $\mathrm{HE}$ diet, was normal ( $P=0.876$, Shapiro-Wilk $W$-test), with an average of $91.3 \pm 1.4 \mathrm{mg} / \mathrm{dl}$ (95\% upper and lower limits). Distributions of glucose level in the blood, measured at weeks 1 to 9, were bimodal and similar 

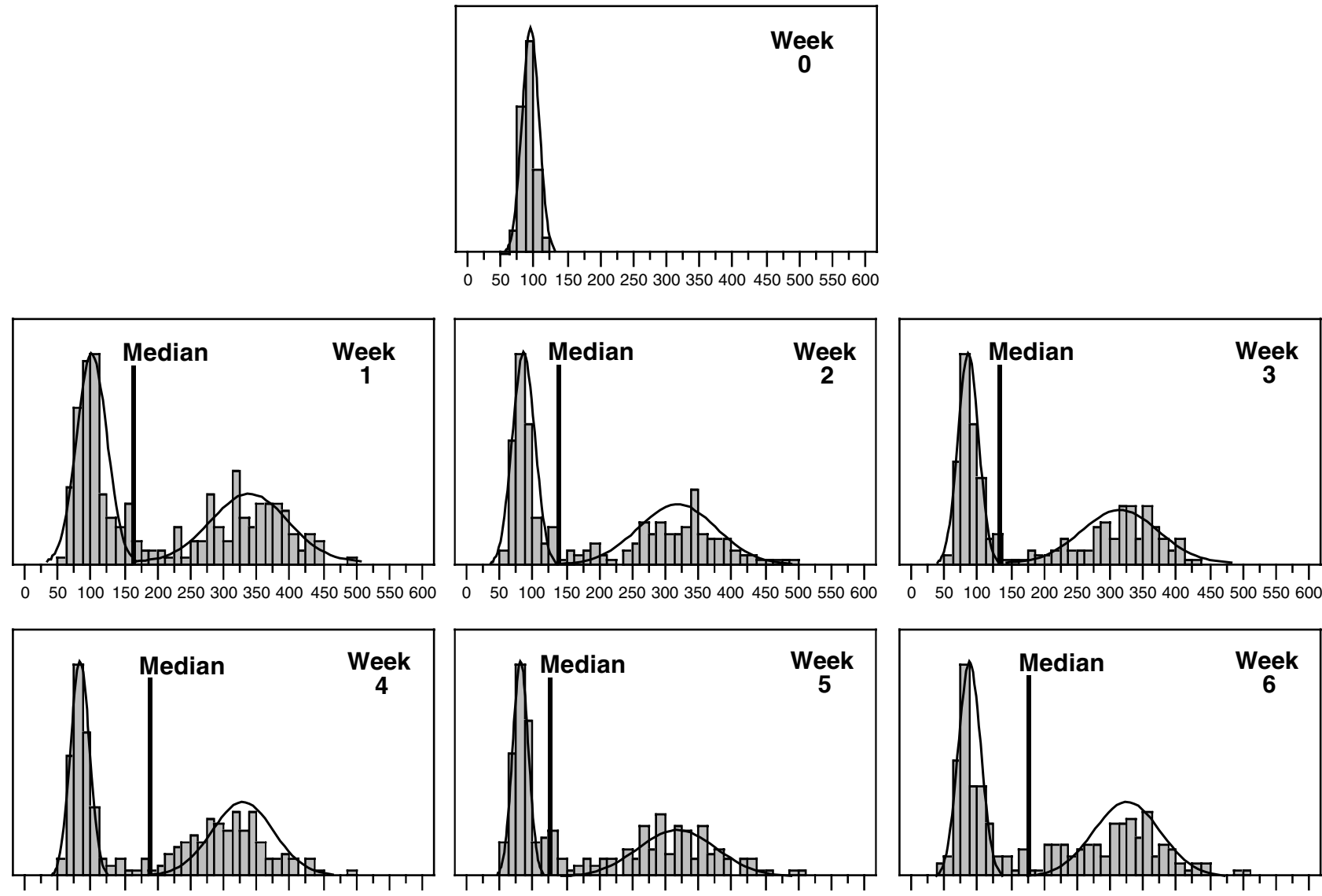

050100150200250300350400450500550600

050100150200250300350400450500550600
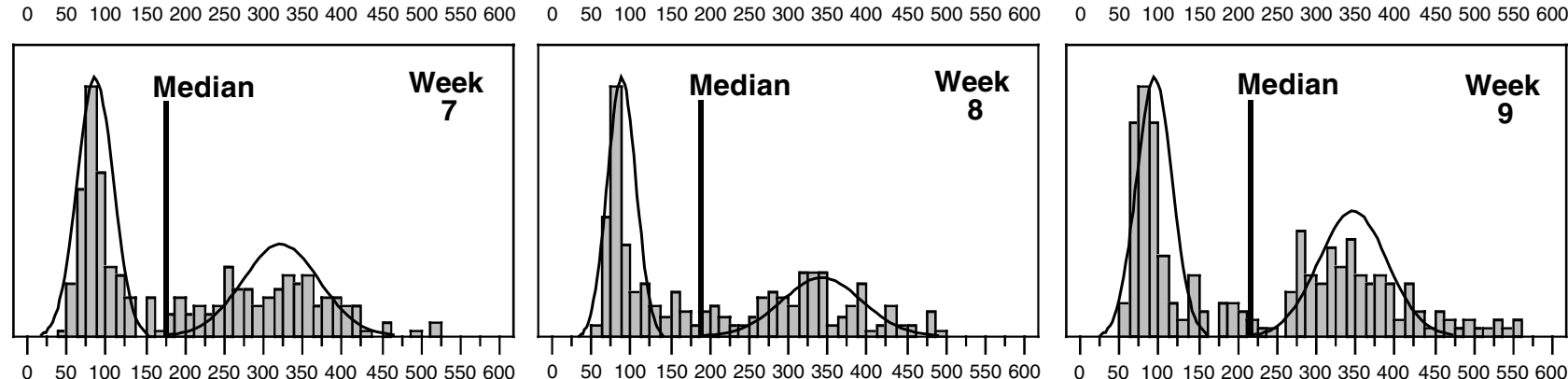

Figure 2 Distribution of blood glucose levels $(\mathrm{mg} / \mathrm{dl})$ in the first backcross generation $\left(\mathrm{BC}_{1}\right)$ at weaning (week 0$)$ and after $1-9$ weeks of $\mathrm{HE}$ diet. Vertical bold lines for weeks 1-9 are the medians of the actual glucose levels for the entire progeny. The smooth curves are the two normal distributions, below and above the median.

for all weeks (Figure 2). For instance, at week 5 when the entire data were partitioned by the median, the average of the low mode (below the media) was $85.3 \pm 3.1 \mathrm{mg} / \mathrm{dl}$ (95\% upper and lower limits) and the average of the high mode (above the median) was $298.5 \pm 15.7 \mathrm{mg} / \mathrm{dl}(95 \%$ upper and lower limits). The distribution around the high mode in week 5 was normal $(P=0.127)$, but the distribution around the low mode was skewed to the right $(P<0.02$, Shapiro-Wilk $W$-test $)$. This wider distribution at the high mode (hyperglycaemia) than at the low mode (normoglycaemia) is typical to all 9 weeks.

\section{Bimodal distribution}

The maximum likelihood procedure describe in the section Subjects, materials and methods has been applied on the glucose data (Table 2). In this table, the maximum likelihood estimates for the means and standard deviations of the two subdistributions at each of the 10 weeks (including week 0) are presented with the appropriate tests for unimodality. Bimodal distributions were visible in all 9 weeks, and our formal test rejected $\mathrm{H}_{0}$ for each of the 9 weeks at very high significance level (Table 2). In contrast, the hypothesis $\mathrm{H}_{0}$ was not rejected when the visible unimodal distribution of the data in week 0 was tested. In Figure 2, a median of the entire progeny has been placed on the distributions for each of the 9 weeks. The two normal distributions below and above the median were drawn, superimposed to the actual data distribution.

In fact, this clear bimodal distribution by itself only is not sufficient to be used as an evidence for a single gene 
Table 2 Maximum likelihood estimates for the bimodal distributions in week 0 and in weeks 1-9 (means $\left(\mu_{1}\right.$ and $\mu_{2}$ ), and standard deviations $\left(\sigma_{1}\right.$ and $\left.\sigma_{2}\right)$ for the low and high means' distributions respectively)

\begin{tabular}{|c|c|c|c|c|c|c|c|}
\hline Week & $\mu_{1}$ & $\sigma_{1}$ & $\mu_{2}$ & $\sigma_{2}$ & Bimodal separation value & $\chi^{2}$ criterion value & Significance $P$ \\
\hline 0 & 91.46 & 11.88 & 91.17 & 8.9 & -0.0070 & 0.3284 & 0.8607 \\
\hline 1 & 102.65 & 23.57 & 324.96 & 72.38 & 1.1583 & 195.58 & $<5 \times 10^{-7}$ \\
\hline 2 & 85.05 & 15.13 & 303.83 & 86.56 & 1.0756 & 247.93 & $<5 \times 10^{-7}$ \\
\hline 3 & 88.36 & 16.84 & 308.54 & 65.21 & 1.3416 & 270.18 & $<5 \times 10^{-7}$ \\
\hline 4 & 85.79 & 13.78 & 297.93 & 70.16 & 1.2635 & 249.22 & $<5 \times 10^{-7}$ \\
\hline 5 & 84.39 & 15.44 & 292.82 & 87.83 & 1.0090 & 230.47 & $<5 \times 10^{-7}$ \\
\hline 6 & 86.62 & 18.85 & 300.94 & 80.53 & 1.0782 & 173.93 & $<5 \times 10^{-7}$ \\
\hline 7 & 86.51 & 18.36 & 300.52 & 87.64 & 1.0094 & 176.28 & $<5 \times 10^{-7}$ \\
\hline 8 & 84.52 & 14.67 & 296.33 & 97.32 & 0.9456 & 161.99 & $<5 \times 10^{-7}$ \\
\hline 9 & 83.66 & 13.69 & 323.90 & 100.38 & 1.0530 & 210.64 & $<5 \times 10^{-7}$ \\
\hline
\end{tabular}

Significance test for unimodality is shown for each of the 10 weeks.

in a backcross generation, unless we show that the two distributions are equal in size, that is, progeny segregation of 1:1.

\section{Progeny segregation}

For a single gene, two genotypes (heterozygotes and homozygotes) are expected in the $\mathrm{BC}_{1}$ generation at a 1:1 ratio, when individuals of generation $\mathrm{F} 1$ are backcrossed to the homozygote recessive parent. To test the goodness of fit of our data to a 1:1 ratio, we used glucose data of the entire progeny distribution in each of the experimental weeks (Figure 2). We identified the minima between the two modes and tested whether this value split the data into two subgroups equal in size.

Separately for each week $i(i=1-9)$, we sorted the glucose levels in ascending order and used these data as an independent variable $\left(x_{i}\right)$. The sequential number from 1 to $n_{i}$ was used as a dependent variable $\left(y_{j}\right)$. The data points were fitted with a polynomial regression equation from the fourth order. Second derivative of the polynomial equation was used to identify the inflection point. The $X$ value (glucose level) of this inflection point was used to partition the $\mathrm{BC}_{1}$ progeny into two subgroups, which were tested against a 1:1 ratio by a chi-square test (Table 3).

Except weeks 2 and 5, in all other 7 weeks, the split into two modes does not deviate from the expected ratio of 1:1, given a single-gene model (Table 2). In weeks 2 and 5 , the number of animals in the low mode relative to that in the high mode is close to the expected 1:1 ratio $-1.14: 0.86$ and 1.18:0.82, respectively. Interestingly, in all 9 weeks, the number of normoglycaemic individuals was slightly larger than the number of hyperglycaemic individuals. This finding might be attributed to a lower survival among the hyperglycaemic animals. On the other hand, we should keep in mind that these are not nine independent observations; it is possible that this is a random difference at week 1 after weaning where diabetes at its early stages should not affect survival, and this single-week difference was kept for the remaining 8 weeks due to high repeatability of the blood glucose level.

\section{Genetic effects}

The estimation approach of the genetic effects (' $d$ ' and ' $h$ ') is presented in Table 1 and the estimates are given in
Table 3 Number of animals in each of the two modes for each of the 9 weeks following HE diet

\begin{tabular}{lcrc}
\hline Week & Low & High & Ratio (Prob.) \\
\hline 1 & 122 & 97 & $1.11: 0.88(0.090)$ \\
2 & 126 & 96 & $1.14: 0.86(0.044)$ \\
3 & 121 & 99 & $1.10: 0.90(0.138)$ \\
4 & 112 & 111 & $1.00: 1.00(0.947)$ \\
5 & 130 & 90 & $1.18: 0.82(0.007)$ \\
6 & 110 & 92 & $1.09: 0.91(0.205)$ \\
7 & 120 & 97 & $1.11: 0.89(0.118)$ \\
8 & 116 & 100 & $1.07: 0.93(0.276)$ \\
9 & 117 & 115 & $1.01: 0.99(0.896)$ \\
\hline
\end{tabular}

Distribution was tested against a null hypothesis of 1:1 using a Pearson $\chi^{2}$ test.

Table 4 Estimation of genetic effects from experimental weeks 1 to 9

\begin{tabular}{lrcc}
\hline Effect & Mean & $\begin{array}{l}\text { Averaged } \\
\text { Std. error }\end{array}$ & Range (week) \\
\hline Midpoint value $(m)$ & 205.4 & 2.3 & $194.9(5)-224.1(9)$ \\
Additive deviation $(d)$ & 114.1 & 2.3 & $103.6(5)-132.8(9)$ \\
Dominant deviation $(h)$ & -111.0 & 4.3 & $106.0(1)-123.9(9)$ \\
\hline
\end{tabular}

Table 4 . The average midpoint value ' $m$ ' over the 9 weeks was 205.4, the genetic additive deviation (d) was 114.1 and the genetic dominant deviation $(h)$ was 111.0. Based on these statistics, the dominance ratio was 0.97 , which indicates complete dominance of the glycaemia-decreasing DR allele.

\section{Consistency of individual's glucose levels over weeks}

If part of the glucose phenotypic variation is caused by genetic factors, consistency of individual performance over the 9 weeks is expected. To represent the apparent genotypes, two subgroups (below and above the median) were chosen according to glucose levels in each of the first 2 weeks. Individuals that were in the highmode distribution in week 1 as well as in week 2 were pooled and termed 'High'. Individuals that were included in the low-mode distribution in these two weeks were pooled and termed as 'Low'. In total, 210 


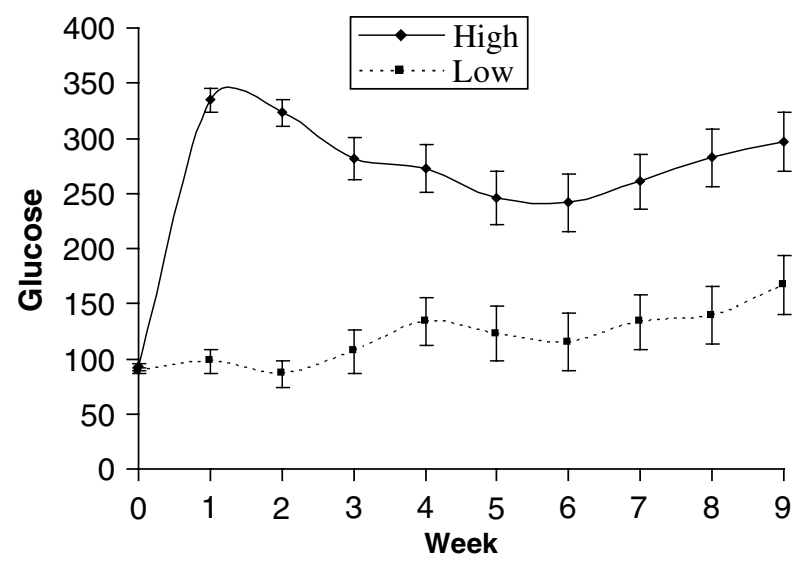

Figure 3 Average glucose levels $(\mathrm{mg} / \mathrm{dl})$ and confidence limits $(\alpha=0.05)$ in 10 weeks of the experiment. Blood glucose levels were averaged across individuals from either 'High' group or 'Low' group, determined according to the blood glucose values of weeks 1 and 2 .

individuals had values in both weeks; 20 switched from low mode in week 1 to high mode in week 2 and 18 vice versa. Average levels of glucose at weeks 0 to 9 for both groups are presented in Figure 3. At week 0 glucose levels were similar for both 'High' and 'Low' groups (92.4 and 90.7, respectively). From week 1 to week 9, a substantial and significant difference between the two groups was apparent $(P<0.0001$, Student's $t$-test). The average difference over weeks between 'High' and 'Low' was $162.4 \mathrm{mg} / \mathrm{dl}$.

We looked for individuals who started the experiment with high levels and ended with low levels (termed 'Recovered'), and vice versa (termed 'Developed'). The normoglycaemic level (nonfasting) was set at $<140 \mathrm{mg} / \mathrm{dl}$ and several threshold levels were selected to represent hyperglycaemia: 200, 250 and $335 \mathrm{mg} / \mathrm{dl}$. Again, to reduce false ascription, we considered individuals as normo- or hyperglycaemic only if in two successive weeks ( 1 and 2 for the start, 8 and 9 for the end) they matched the threshold criterion. Relatively few individuals were found to switch their mode. More individuals were found to develop hyperglycaemia than to recover from it, regardless of the threshold value $(X)$ for considering an individual as hyperglycaemic. At a maximum $(X=200)$, only $14(6 \%)$ individuals alternated their glucose values from low to high and only eight (4\%) individuals from high to low. When the threshold was set to $335 \mathrm{mg} / \mathrm{dl}$, no animals were in the 'Recovered' group and only $2 \%$ were in the 'Developed' group. These findings indicate high consistency $(90 \%)$ of the discrimination between DP and DR animals, which appears to be determined in less than a week upon a transfer to the HE diet.

\section{Body weight of the apparent genotypes}

Body weights of the 'High' and 'Low' groups of blood glucose levels were compared in all 10 weeks of the experiment. The results are presented in Figure 4. Apparently, body weight increases over the experimental weeks (1-9). The increase was nonlinear but similar for both groups. Interestingly, at week 0 , body weight of the

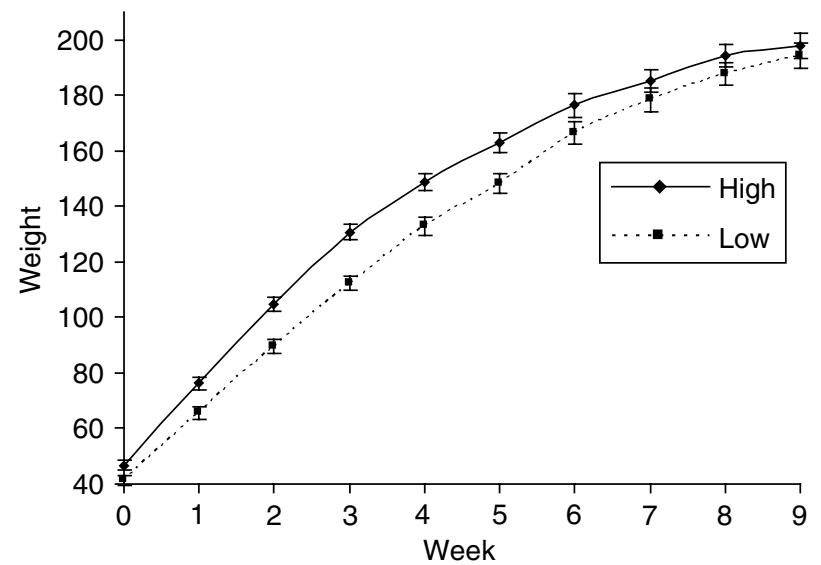

Figure 4 Average body weight (grams) and confidence limits $(\alpha=0.05)$ in 10 weeks of the experiment. 'High' and 'Low' groups are according to levels of blood glucose values of weeks 1 and 2, as in Figure 3.

'High' glucose group was higher by $5.7 \mathrm{~g}(13 \%)$ than that of the 'Low' group $(P<0.0001$, Student's $t$-test). Except for week 9, body weight of the 'High' glucose group was significantly higher than that of the 'Low' group in all weeks $(P<0.05$, Student's $t$-test).

\section{Discussion}

The bimodal distribution of the blood glucose concentration in generation $\mathrm{BC}_{1}$, with a similar number of individuals in the two subdistributions, is the key finding of this report. This distribution of progeny suggests that a major gene may be involved in the transition from normoglycaemia to hyperglycaemia, while the level of the blood glucose within each mode may be affected by more than one gene and by environmental factors. If this hypothesis is true, it implies that the selected DR line is homozygous for the dominant allele, the selected DP line is homozygous for the recessive allele, and that F1 is heterozygous for this single putative gene. In such a case, when F1 individuals are backcrossed to the DP line, one should expect a bimodal distribution among the $\mathrm{BC}_{1}$ progeny at a ratio of 1:1 between the resistant and the prone modes. In fact, we used the backcross to the DP line rather than to the DR line or to both lines, since we hypothesized that the hyperglycaemic animals are more likely to be homozygous recessive.

The $\mathrm{BC}$ genetic design has been used extensively to test bimodality as an indication for a major gene affecting the trait. For instance, Ohno et al (2000) used it for mapping a major QTL affecting hypertension in rats. Similarly, Rapp (1982) detected autosomal locus (partially dominant) controlling vascular smooth muscle response in spontaneously hypertensive rats. In contrast, the absence of a bimodal distribution in generation $\mathrm{BC}_{1}$ has been used by Franko et al (1996) and Jones and Kusel (1985) as evidence for polygenic rather than monogenic inheritance.

Our study indicates that diabetes susceptibility may be the result of a recessive genetic background. Psammomys 
was demonstrated to have a low density of insulin receptors in muscle and liver (Kanety et al, 1994), low GLUT4 protein (Shafrir et al, 1999b) and low PTPase activites (Meyerovitch et al, 2002). These attributes of a desert-adjusted animal limit its capacity to cope with nutritional surplus. In addition, DP Psammomys even in the normoglycaemic stage exhibits elements of insulin resistance, as evidenced by the inability to lapse into hypoglycaemia, lose liver glycogen and restrain the hepatic glucose production after administration of exogenous insulin (Ziv et al, 1996). This was in marked contrast to the hypoglycaemic and gluconeogenesis suppression response of the insulin-treated laboratory albino rats (Ziv et al, 1996). These properties have been ascribed to increased expression of protein kinase $c$ isoenzyme $\varepsilon(\mathrm{PKC} \varepsilon)$, which inhibits the activity of tyrosine kinase, PKB and lowers GLUT 4 protein (Shafrir et al, 1999a; Ikeda et al, 2001). The primary PKC $\varepsilon-$ associated insulin resistance in Psammomys appears to be species characteristic of an animal adjusted to subsist on meager nutrition in a desert environment and may be the result of polygenic recessive control. On the other hand, the hyperglycaemia and hyperinsulinaemia elicited by overnutrition appear to be affected by a major dominant gene expressing the functional disorders elicited by the inappropriately abundant environment. Fortunately, these deleterious changes are reversible if the return to LE nutrition is imposed promptly, before lasting changes in the $\beta$-cells occur (Shafrir et al, 1999a). The behavior of Psammomys may reflect the exceptional inclination to insulin resistance and diabetes-inducing effect of overnutrition in certain human population groups. It may be of interest that the propensity to diabetes in the Mexican-American population has also been ascribed by Stern et al (1996) to the effect of a major gene which is dominant on the background of environmental predisposition. Although several genes related to energy balance and hyperglycaemia have been already isolated in specific tissues of Psammomys (Collier et al, 2000; Walder et al, 2002), our main conclusion is to challenge the polygenic approach to the development of insulin resistance and T2D. We have shown that, in an established dietary regimen defined by us, a major gene comes into play. This gene may mask what might be a polygenic-based phenomenon in another environment. Thus, what may be polygenic in one environment with a neutralized major gene may be monogenic in another environment where that gene becomes expressed. Such result may have large implications to the human situation where individuals overconsume. We propose that a major monogenic factor initiates T2D, which may be followed or associated with nutritionally and/or environmentally evoked factors. This approach may apply to the development of T2D in animals and humans alike.

The possible existence of a single gene involved in the transition from normoglycaemia to hyperglycaemia in Psammomys calls for special efforts to isolate this gene, using advanced genomics technologies.

\section{References}

Alcolado JC, Thomas AW (1995). Maternally inherited diabetes mellitus: the role of mitochondrial DNA defects. Diab Med 12: 102-108.
Chajek-Shaul T, Ziv E, Friedman G, Etienne J, Adler J (1988). Regulation of lipoprotein lipase activity in the sand rat: effect of nutritional state and cAMP modulation. Metabolism 37: 1152-1158.

Coleman DL (1978). Diabetes and obesity: thrifty mutants? Nutr Rev 36: 129-132.

Collier GR, McMillan JS, Windmill K, Walder K, Tenne-Brown J, de Silva A (2000). Beacon: a novel gene involved in the regulation of energy balance. Diabetes 49: 1766-1771.

Franko AJ, Sharplin J, Ward WF, Taylor JM (1996). Evidence for two patterns of inheritance of sensitivity to induction of lung fibrosis in mice by radiation, one of which involves two genes. Radiat Res 146: 68-74.

Ikeda Y, Olsen GS, Ziv E, Hansen LL, Busch AK, Hansen BF et al (2001). Cellular mechanism of nutritionally induced insulin resistance in Psammomys obesus: overexpression of protein kinase $C_{\varepsilon}$ in skeletal muscle precedes the onset of hyperinsulinemia and hyperglycemia. Diabetes 50: 584-592.

$\mathrm{JMP}^{\mathbb{R}}$, Statistical Discovery Software (version 40). SAS Institute Inc.: NC, USA.

Jones JT, Kusel JR (1985). The inheritance of responses to Schistosomiasis mansoni in two pairs of inbred strains of mice. Parasitology 90: 289-300.

Kalman R, Ziv E, Adler JH, Lazarovici G, Bar-On H (1993). The efficiency of sand rat metabolism is responsible for the development of obesity and diabetes. I Basic Clin Physiol Pharmacol 4: 57-88.

Kanety H, Moshe S, Shafrir E, Lunenfeld B, Karasik A (1994). Hyperinsulinemia induces a reversible impairment in insulin receptor function leading to diabetes in the sand rat model of non-insulin-dependent diabetes mellitus. Proc Natl Acad Sci 91: $1853-1857$.

Mather K, Jinks J (1971). Biometrical Genetics. Cornell University Press: Ithaca, NY.

Meyerovitch J, Balta Y, Ziv E, Sack J, Shafrir E (2002). Protein tyrosine phosphatase activity in insulin-resistant rodent Psammomys obesus. Int J Exp Diab Res 3: 199-204.

Nathan DM (2002). Initial management of glycemia in type 2 diabetes mellitus. $N$ Engl J Med 347: 1342-1349.

Neter J, Wasserman W (1974). Applied Linear Statistical Methods. Richard D. Irwin Publishers: Homewood, Illinois.

Ohno Y, Tanase H, Nabika T, Otsuka K, Sasaki T, Suzawa T (2000). Selective genotyping with epistasis can be utilized for a major quantitative trait locus mapping of hypertension in rats. Genetics 155: 785-792.

Poulsen P, Kyvik KO, Vaag A, Beck-Nielsen H (1999). Heritability of Type II (non-insulin dependent) diabetes mellitus and abnormal glucose tolerance: a population based twin study. Diabetologia 42: 139-145.

Pruhova S, Ek J, Lebl J, Sumnik Z, Saudek F, Andel M et al (2003). Genetic epidemiology of MODY in the Czech republic: new mutations in the MODY genes HNF- $4 \alpha$, GCK and HNF-1 $\alpha$. Diabetologia 46: 291-295.

Rapp JP (1982. A genetic locus (Hyp-2) controlling vascular smooth muscle response in spontaneously hypertensive rats. Hypertension 4: 459-467.

Shafrir E (1996). Development and consequences of insulin resistance: lessons from animals with hyperinsulinemia. Diab Metab 22: 122-131.

Shafrir E, Ben-Sasson R, Ziv E, Bar-On H (1999a). Insulin resistance, beta cell survival and apoptosis in type 2 diabetes: animal models and human implications. Diab Rev 7: 114-123.

Shafrir E, Ziv E, Mosthaf L (1999b). Nutritionally induced insulin resistance and receptor defect leading to beta cell failure in animal models - human implications. Ann NY Acad Sci 892: 223-246.

Stern MP, Mitchell BD, Blangero J, Reinhart L (1996). Evidence for a major gene for type II diabetes and linkage analyses with selected candidate genes in Mexican Americans. Diabetes 45: 563-568. 
Tsigos C, Kyrou I, Raptis SA (2002). Monogenic forms of obesity and diabetes mellitus. J Pediatr Endocrinol Metab 15: 241-253.

Walder K, Kantham L, McMillan JS, Trevaskis J, Kerr L, de Silva A et al (2002). Tanis: a link between type 2 diabetes and inflammation? Diabetes 51: 1859-1866.

Zhang C, Mapes BE, Soden BJ (2003). Bimodality in tropical water vapour. QJR Meteorol Soc 129: 2847-2866.

Zimmet P, Alberti KGMM, Shaw J (2001). Global and societal implications of the diabetes epidemic. Nature 414: 782-787.
Ziv E, Kalman R (2000). Psammomys obesus: primary insulin resistance leading to nutritionally induced type 2 diabetes. In: Sima AAF, Shafrir E (eds) Animal Models of Diabetes, A Primer. Harwood Academic Publishers: The Netherlands. pp 327-342.

Ziv E, Kalman R, Hershkop K, Barash V, Shafrir E, Bar-On H (1996). Insulin resistance in the NIDDM model Psammomys obesus in the normoglycaemic-normoinsulinaemic state. Diabetologia 39: 1269-1275. 